Subscriber access provided by READING UNIV

Article

\title{
Development and Fidelity Evaluation of a Skeletal Ethylene Mechanism under Scramjet-Relevant Conditions
}

\author{
Kun Wu, Wei Yao, and Xuejun Fan
}

Energy Fuels, Just Accepted Manuscript • DOI: 10.1021/acs.energyfuels.7b03033 • Publication Date (Web): 29 Nov 2017

Downloaded from http://pubs.acs.org on December 1, 2017

\section{Just Accepted}

"Just Accepted" manuscripts have been peer-reviewed and accepted for publication. They are posted online prior to technical editing, formatting for publication and author proofing. The American Chemical Society provides "Just Accepted" as a free service to the research community to expedite the dissemination of scientific material as soon as possible after acceptance. "Just Accepted" manuscripts appear in full in PDF format accompanied by an HTML abstract. "Just Accepted" manuscripts have been fully peer reviewed, but should not be considered the official version of record. They are accessible to all readers and citable by the Digital Object Identifier (DOI®). "Just Accepted" is an optional service offered to authors. Therefore, the "Just Accepted" Web site may not include all articles that will be published in the journal. After a manuscript is technically edited and formatted, it will be removed from the "Just Accepted" Web site and published as an ASAP article. Note that technical editing may introduce minor changes to the manuscript text and/or graphics which could affect content, and all legal disclaimers and ethical guidelines that apply to the journal pertain. ACS cannot be held responsible for errors or consequences arising from the use of information contained in these "Just Accepted" manuscripts. 


\title{
Development and Fidelity Evaluation of a Skeletal
}

\section{Ethylene Mechanism under Scramjet-Relevant}

\section{Conditions}

\author{
Kun $W^{\dagger, \ddagger}$, Wei Yao ${ }^{\dagger, \dagger, *}$ and Xuejun Fan ${ }^{\dagger, \dagger, *}$ \\ ${ }^{\dagger}$ State Key Laboratory of High Temperature Gas Dynamics, Institute of Mechanics, Chinese \\ Academy of Sciences, Beijing, 100190, People's Republic of China \\ \$School of Engineering Sciences, University of Chinese Academy of Sciences, Beijing 100049, \\ People's Republic of China
}

KEYWORDS: Ethylene; DRGEP; SA; CSP; Fidelity; Scramjet; LES

\begin{abstract}
As one of the major short chain hydrocarbons resulting from the cracking process, ethylene is often used as a surrogate for cracked kerosene. In this study, a skeletal mechanism of ethylene was developed under the typical working conditions of scramjet combustors. The skeletal mechanism was reduced from a fully verified detailed mechanism under the desired working conditions. An integrated reducing method containing directed relation graph with error
\end{abstract}


propagation method (DRGEP), sensitivity analysis (SA) and computational singular perturbation (CSP) was employed to obtain three skeletal mechanisms. A three-level fidelity validation of the skeletal mechanisms respectively comparing the kinetic properties, the global combustor performance and the detailed flame structure was proposed to comprehensively evaluate the skeletal mechanisms. In the first-level fidelity validation, the three skeletal mechanisms all show good agreements with the detailed one in the autoignition delay and laminar flame speed over a wide range of working conditions. Then in the second-level fidelity validation, the smallest mechanism consisting of 24 species and 86 reactions $(24 \mathrm{~S} / 86 \mathrm{R})$ was further validated through incorporating with the large eddy simulation of a realistic scramjet combustor. Comparisons with the experimental data and the predictions by the detailed mechanism show that the global combustor performance (e.g., pressure, Mach number and combustion efficiency) was accurately predicted by the $24 \mathrm{~S} / 86 \mathrm{R}$ mechanism. In the third-level fidelity evaluation, the flame structure characterized by the distribution of $\mathrm{CO}, \mathrm{OH}$ and heat release rate was analyzed through comparing the predictions by the $24 \mathrm{~S} / 86 \mathrm{R}$ mechanism with those by the detailed one during which the insufficiency of the skeletal mechanism was also recognized. 


\section{INTRODUCTION}

Scramjet is an attractive technology for powering hypersonic vehicles. They introduce mechanical simplicity through a lack of moving parts and an increase in efficiency over rocket propulsion benefiting from their air-breathing characteristics. However, due to the experimental difficulties, a complete understanding of their internal flow, mixing and combustion processes is still lacking. With the advance of high-performance computation techniques, high-resolution large eddy simulation (LES) is playing an important role in revealing some of the supersonic combustion physics, e.g., the ignition ${ }^{1}$, the flame stabilization ${ }^{2}$ and the combustion instability ${ }^{3}$.

A prior thing to the numerical modeling is to find high-fidelity yet computational efficient chemical mechanisms. In the early scramjet designs, hydrogen is usually preferred due to its high reactivity and heat of combustion. However, for practical use, hydrocarbon fuels (e.g., kerosene) are more economical in the manufacture, storage and flight carrying. ${ }^{4}$ As one of the major products resulting from the cracking process of complex hydrocarbons, ethylene is often used as a surrogate for the cracked kerosene $e^{5}$. However, even as a pure species, the combustion of ethylene still involves hundreds of species and thousands reactions. Therefore, reduced or global mechanisms are often used instead. ${ }^{6}$

In addition to the reduction in mechanism size, the fidelity of the mechanism needs to be fully validated. Usually, mechanism reductions are conducted only under a single property target, i.e., the ignition delay or the laminar flame speed with predefined error threshold. While the other kinetic properties still need further posterior validations to confirm the fidelity of the reduced mechanisms. More importantly, the complexity induced by turbulence-chemistry interaction (TCI) in turbulent reacting flow requires a higher fidelity for the reduced mechanism. Therefore rules to comprehensively evaluate the accuracy of the reduced mechanism should be designed. 
As a base level of fidelity validation, multiple property targets (e.g., ignition delay, laminar flame speed, flame temperature, total heat release and extinction strain rate) should be compared with the original detailed mechanism. Such base level fidelity validation ${ }^{7}$ considers little the flow effect. The second level of fidelity validation needs to couple the mechanism with the reacting flows for which it is initially designed. The second level of fidelity validation compares the predictions by the reduced mechanism with experimental data or those by the detailed mechanism. For example, Hui et al. ${ }^{8}$ and Wang et al. ${ }^{9}$ compared the capability of the skeletal mechanism in predicting the pressure profiles in HCCI-like engine and compression ignition engine simulation. For scramjet combustor modeling, Yao et al. ${ }^{10}$ validated the second level of mechanism fidelity by comparing with the experimental pressure distribution which is often the only available data from scramjet experiments. The above levels of fidelity validations care about only the steady statuses, while the third level of fidelity validation cares about the accurate predictions of intermediate species when the modeling focuses on unsteady combustion processes, such as the ignition and flame stabilization. Especially in supersonic combustion, puny deficiency in the skeletal mechanism such as $10^{-4} \mathrm{~s}$ error in ignition delay time will be magnified into $\sim 0.1 \mathrm{~m}$ error in ignition distance in supersonic flow. Regarding the third level of fidelity evaluation about chemical kinetics, scarce work can be found at present due to the lack of detailed experimental data.

This study will elaborate the integrated process of skeletal mechanism development for scramjet combustor modeling along with its fidelity evaluation on basic kinetic properties as well as its accuracy in realistic scramjet modeling. The mechanism reduction is presented in section 2 , followed by the first level of fidelity validation in section 3. The experimental and numerical 


\subsection{Verification of the Detailed Mechanisms}

The kinetic properties of the detailed mechanisms will be validated under typical working conditions of scramjet, which are temperature from 1000 to $2000 \mathrm{~K}$, global equivalence ratio from 0.5 to 2.0 , and pressure around $1.0 \mathrm{~atm} .{ }^{19}$ Both ignition delay and laminar flame speed will be compared with the experimental data. The SENKIN subroutine program of the CHEMKIN II package $^{20}$ is used to calculate the ignition delay under constant pressure and adiabatic conditions. The ignition delay is registered as the inflection on the $\mathrm{OH}$ concentration profile.

Figure 1 shows the ignition delay time for the five detailed mechanisms together with experimental data $^{21}$ at different pressures. In Figure 1(a), where the pressure is close to the 
standard atmospheric pressure, the UCSD and UCSII mechanisms show extremely good agreement with the experimental data. The Qin mechanism reproduces a similar trend but considerably overpredicts the magnitude. The Laskin mechanism underpredicts the ignition delay in the low-temperature range while well predicts above $1425 \mathrm{~K}$. On the contrary, the GRI 3.0 mechanism overpredicts the ignition delay on the high-temperature side. With increased pressure, the prediction by the UCSD mechanism still closely follows the experimental data while the UCSII under predicts on the low-temperature range. The Qin mechanism still overpredicts the ignition delay on the entire temperature range where experimental measurements available. For the GRI 3.0 mechanism, its prediction agrees better at the elevated pressure, but the deviations still exist in the low-temperature range.

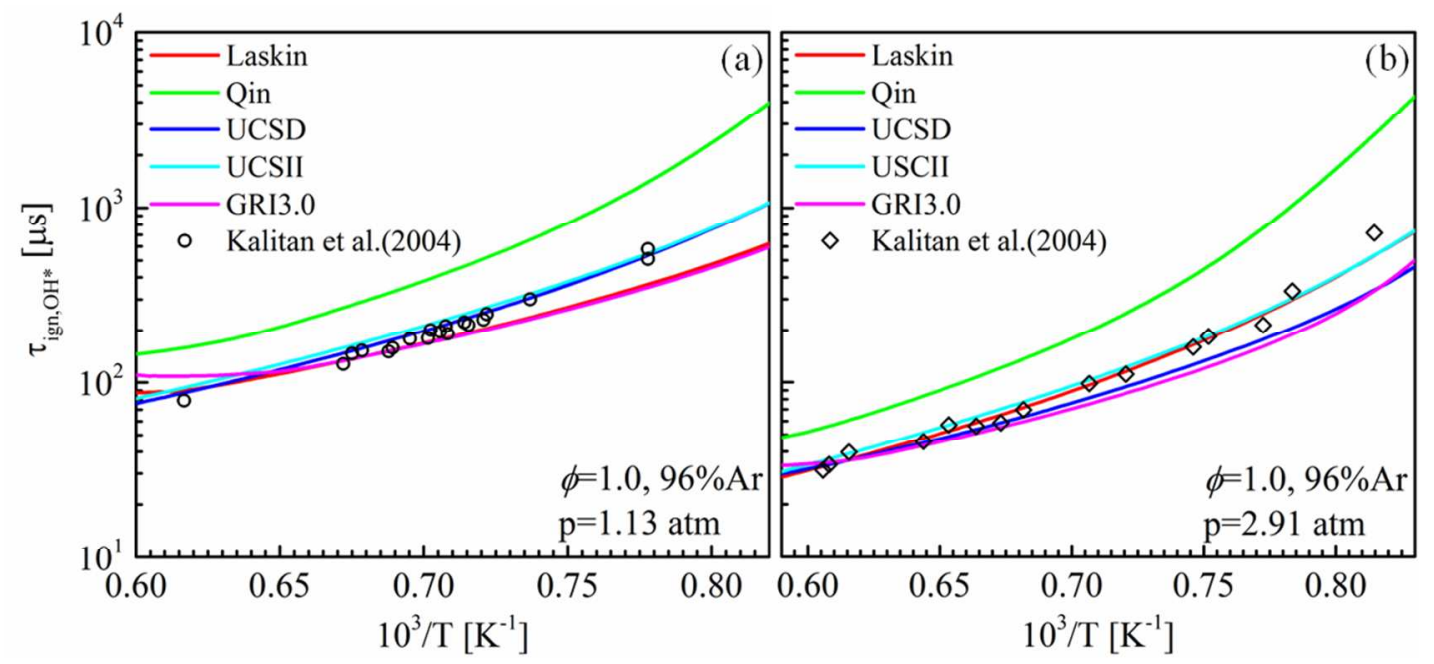

Figure 1. Ignition delays predicted by different detailed mechanisms, and the experimental data from Kalitan et al. ${ }^{22}$ for pressure (a) $1.13 \mathrm{~atm}$, and (b) $2.91 \mathrm{~atm}$.

The laminar flame speed $\mathrm{S}_{\mathrm{u}}$ is calculated by the PREMIX subroutine of the CHEMKIN II package for stoichiometric ethylene-air mixture under $1.0 \mathrm{~atm}$ and initial temperature of $298 \mathrm{~K}$. Figure 2 (a) and (b) compare the predictions with two different sets of experimental data. The GRI 3.0 mechanism considerably over predicted $\mathrm{S}_{\mathrm{u}}$, with averaged relative errors of $27.9 \%$ and 
$20.8 \%$ respectively compared with the data from Egolfopoulos et al. ${ }^{23}$ and Kumar et al. ${ }^{22}$. The Qin and UCSD mechanisms show good agreements with the both data sets. The prediction by the Laskin mechanism is fairly good but with slightly larger errors. More quantitative comparisons are listed in the supporting information.
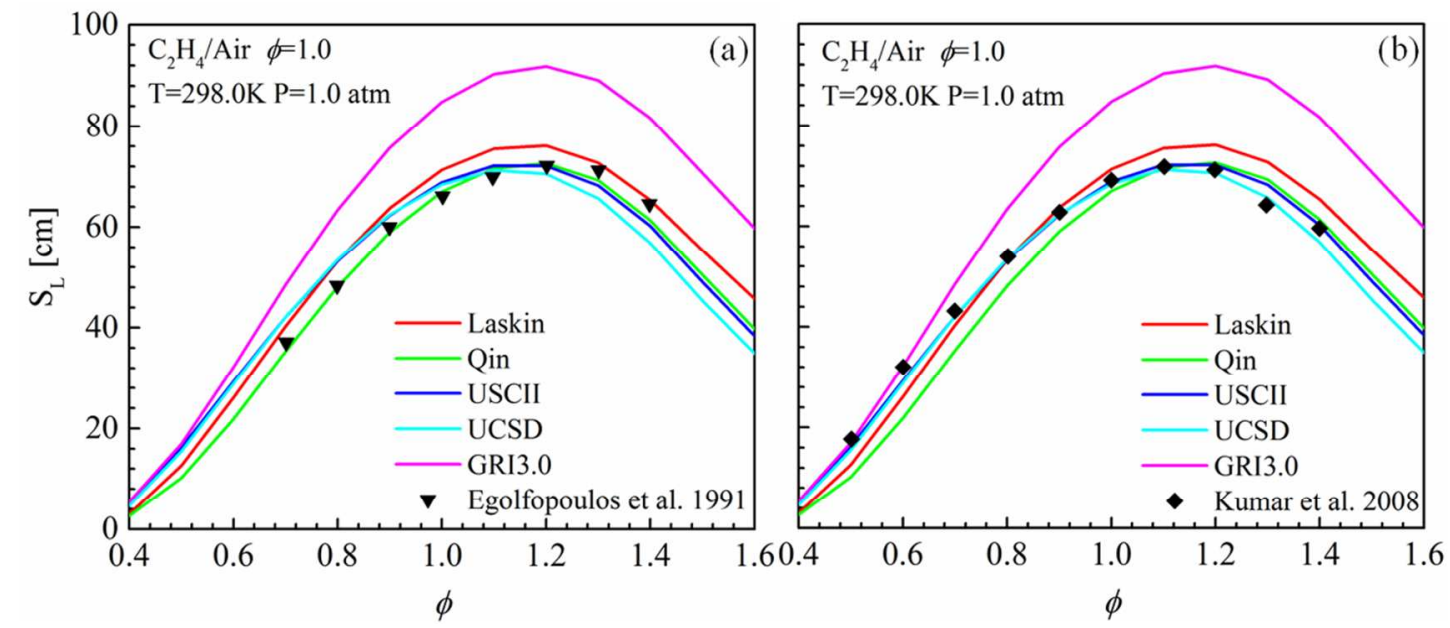

Figure 2. Laminar flame speeds predicted by different detailed mechanisms, and the experimental data at $p=1.0 \mathrm{~atm}$ and $T=298 \mathrm{~K}$ for stoichiometric ethylene/air mixture.

From the above comparisons, the UCSD and USCII mechanisms outperform the other mechanisms in the desired operating conditions. Since the UCSD mechanism is smaller than the UCSII mechanism, it is selected as the base mechanism for the following reduction.

\subsection{Reduction Methodology and Procedures}

A number of mechanism reduction methods have been developed in recent years, as reviewed by Lu et al. ${ }^{24}$ The various method can be roughly divided into serval categories. Most methods focus on identifying and trimming unimportant species and their associated reactions, including sensitivity analysis ${ }^{25}, \mathrm{DRG}^{26}, \mathrm{DRG}$ with error propagation (DRGEP) ${ }^{27}$, DRG-aided sensitivity analysis $(\mathrm{DRGSA})^{28}$ and path flux analysis $(\mathrm{PFA})^{7}$. Other reduction methods focus on time-scale analysis, splitting the reaction into fast and slow manifolds then removing the short time-scales 
which cause chemical stiffness. These approaches rely on the classical quasi-steady state (QSS) ${ }^{29}$ and partial equilibrium approximations $(\mathrm{PEA})^{30}$, including intrinsic low dimensional manifold $(\mathrm{ILDM})^{31}$, and computational singular perturbation $(\mathrm{CSP})^{32}$.

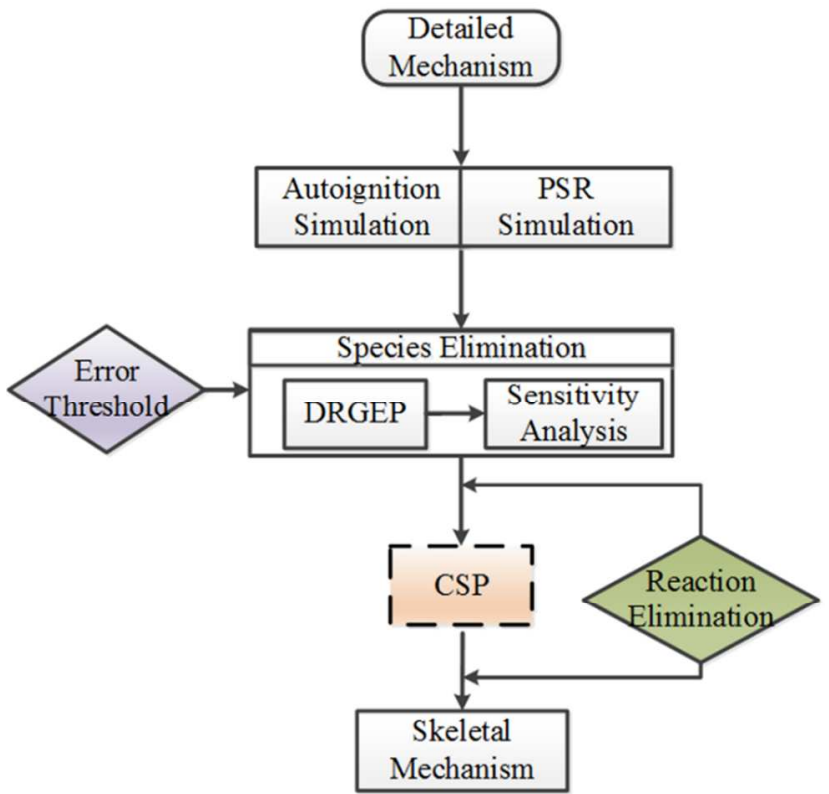

Figure 3. Flow chart of the integrated mechanism reduction method used in the present study.

In this study, as visualized in Figure 3, an integrated reduction method of DRGEP, SA and CSP was used to construct the skeletal mechanism. The reduction procedure used both autoignition and PSR simulations to generate the thermochemical data and evaluate the resulting skeletal mechanism's performance. Firstly, DRGEP is used to quantify the relative importance of each species to the predetermined target species, which were chosen as $\mathrm{C}_{2} \mathrm{H}_{4}, \mathrm{O}_{2}$ and $\mathrm{N}_{2}$ following Niemeyer et al. ${ }^{28,33}$. The initial conditions of the auto-ignition simulations are 1000$1800 \mathrm{~K}$ for temperature, 1.0-5.0 atm for pressure, and 0.5-1.5 for $\phi$ (overall equivalence ratio, ethylene/air mixture). Here the interested temperature is above $1000 \mathrm{~K}$ since the mechanism is developed for scramjet modeling. The threshold for ignition delay error in the DRGEP stage is 
set to $10 \%$. Table 2 shows that most of the unimportant species have been filtered out by the DRGEP to produce a skeletal mechanism near half-sized.

Table 2. Comparison for three different assemblies of methods

\begin{tabular}{|r|c|c|c|c|c|c|}
\hline & \multicolumn{2}{|c|}{ DRGEP } & \multicolumn{2}{c|}{ DRGEPSA } & \multicolumn{2}{c|}{ RGEPSACSP } \\
\hline$\delta_{\text {DRGEP }}$ & $\mathrm{S}$ & $\mathrm{R}$ & $\mathrm{S}$ & $\mathrm{R}$ & $\mathrm{S}$ & $\mathrm{R}$ \\
\hline 0.00 & 57 & 269 & 57 & 269 & 57 & 269 \\
\hline 0.05 & 30 & 143 & 26 & 114 & 26 & 102 \\
\hline 0.10 & 30 & 143 & 24 & 101 & 24 & 86 \\
\hline Final & \multicolumn{3}{|c|}{$\delta_{\text {DRGEP }}=10 \%$} & \multicolumn{3}{|c|}{$\delta_{\mathrm{SA}}=10 \%$ and $\delta_{\mathrm{CSP}}=10 \%$} \\
\hline
\end{tabular}

SA and CSP are subsequently applied to further reduce the mechanism. The SA phase was carried out with an error limit of $10 \%$ by using the SENKIN subroutine of the CHEMKIN II package. After the SA phase, $20 \%$ of the remaining species were removed. Further application of CSP to identify and trim the reactions in fast manifold can still remove near $15 \%$ reactions of the mechanism from the SA phase. Three sets of skeletal mechanisms shown in Table 2 are constructed by using different combinations of DRGEP, SA and CSP, namely DRGEP (30 species and 143 reactions, referred to 30S/143R), DRGEPSA (24S/101R) and DRGEPSACSP (24S/86R).

\section{FIRST LEVEL OF FIDELITY EVALUATION OF THE PROPOSED MECHANISM}

\subsection{Homogeneous Auto-ignition}

Figure 4(a) compares the ignition delay times for stoichiometric ethylene-air mixture at $\mathrm{p}=1.0 \mathrm{~atm}$ predicted by the skeletal and detailed mechanisms. Below $1350 \mathrm{~K}$, the predictions by the three skeletal mechanisms all agree well with those given by the detailed mechanism. Above $1350 \mathrm{~K}$, the three skeletal mechanisms predict a maximum discrepancy of 5\% compared with thoes by the detailed mechanism. Furthermore, the time evolution of temperature for 
ethylene-air mixture at the same pressure and equivalence ratio condition is presented in Figure 4(b) shows that for initial temperatures ranging from 1100 to $1700 \mathrm{~K}$, the time-variant temperature profiles predicted by three skeletal mechanisms all agree well with that of the detailed mechanism.
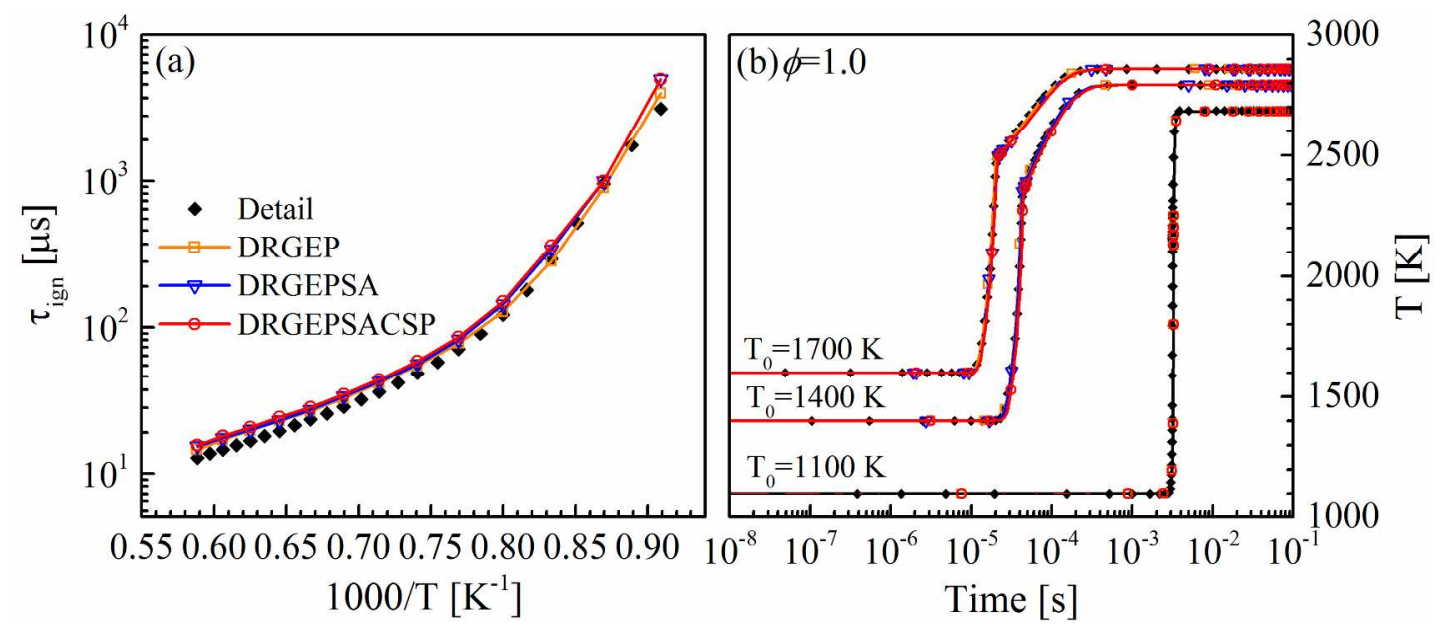

Figure 4. Comparisons of (a) ignition delay time, and (b) temperature response for the skeletal and detailed mechanisms under $p=1.0$ atm and $\phi=1.0$ for ethylene-air mixture.

Figure 5 presents the validations for initial temperatures of $1100 \mathrm{~K}, 1300 \mathrm{~K}, 1500 \mathrm{~K}$ and 1700 $\mathrm{K}$ under both fuel lean $(\phi=0.5)$ and rich $(\phi=1.5)$ conditions. The time-evolution of temperature predicted by the three skeletal mechanisms are indistinguishable with the one by the detailed mechanism over the entire ignition process. The above validations confirm that the kinetic properties related to ignition are properly retained after the reduction. 


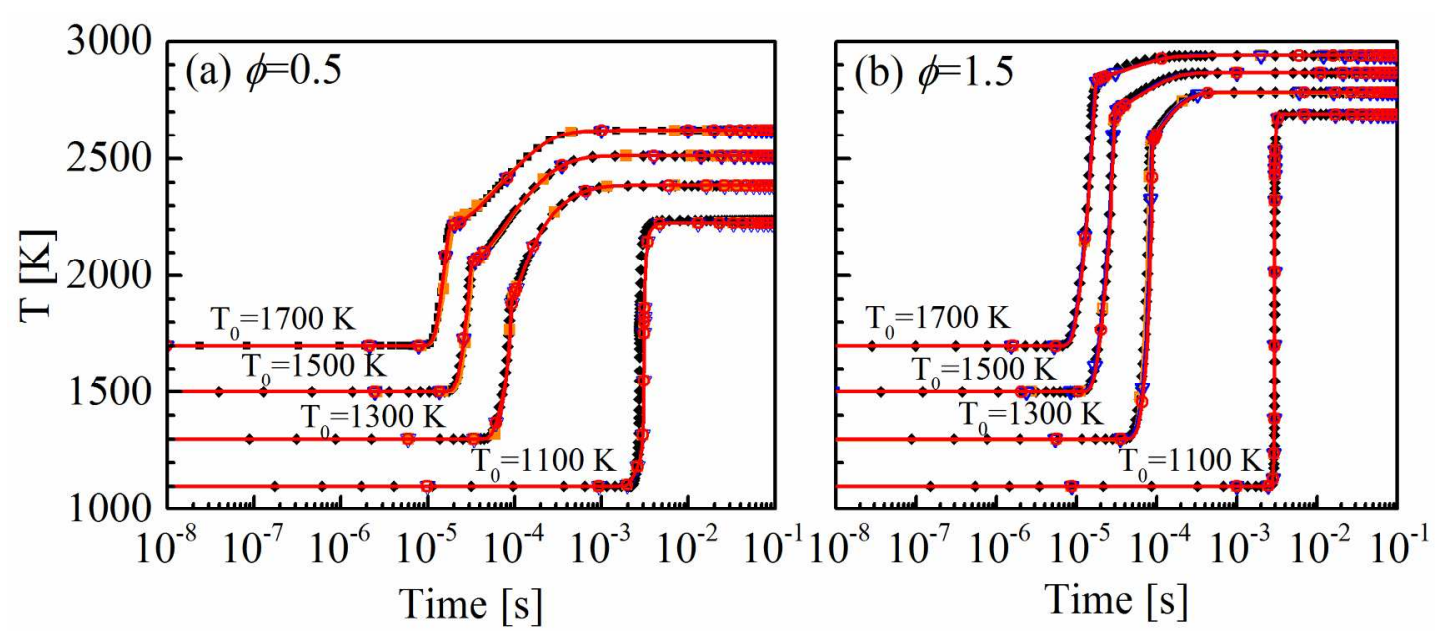

Figure 5. Comparisons of temperature response at $\phi$ (a) 0.5 and (b) 1.5 for the skeletal and detailed mechanisms under $p=1.0$ atm for ethylene-air mixture.

\subsection{Laminar Flame Speed}

Figure 6 compares the laminar flame speeds predicted by the skeletal mechanisms and the detailed mechanism. The skeletal mechanism commonly shows good agreement with its detailed contour-part at the fuel lean condition ${ }^{34}$ as also shown in Figure 6(a). However, at fuel-rich conditions, the DRGEPSA and DRGEPSACSP mechanisms slightly overpredict the laminar flame speed with a maximum relative error of $1.5 \%$, while the predictions by the DRGEP mechanism still show reasonably good agreement with those by the detailed mechanism. From Figure 6(b), the spatial distributions of the major species predicted by the three skeletal mechanisms show excellent agreement with those by the detailed mechanism. Here the $\mathrm{H}_{2} \mathrm{O}$ and $\mathrm{CO}_{2}$ are selected because they are the main products in combustion systems. 

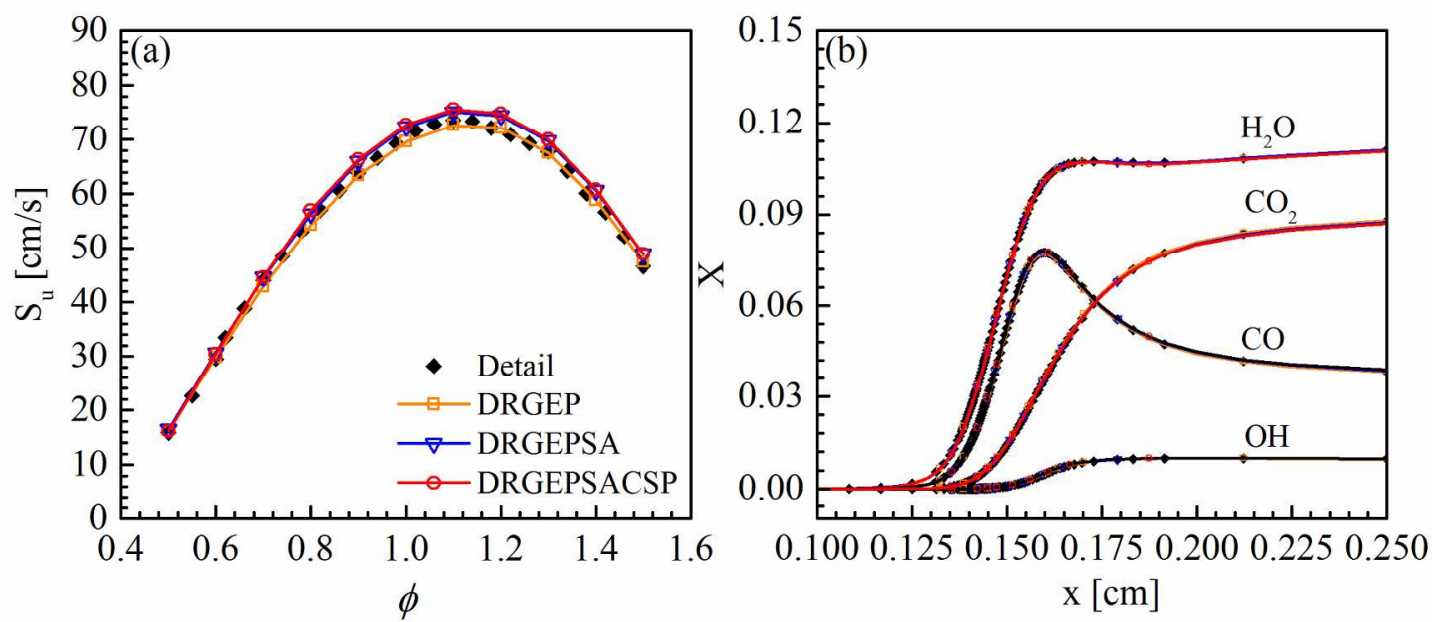

Figure 6. Comparisons of (a) laminar flame speed and (b) species distribution for the skeletal and detailed mechanisms for stoichiometric ethylene-air mixture under $T=298 \mathrm{~K}, p=1.0$.

Figure 7 presents sensitivity of laminar flame speed to the ten most sensitive reactions for different mechanisms under the stoichiometric condition, temperature of $298 \mathrm{~K}$ and pressure of $1.0 \mathrm{~atm}$. It can be seen that the laminar flame speed in the detailed mechanism is mostly influenced by the reactions in the $\mathrm{H} / \mathrm{O} / \mathrm{C}_{1}$ subset, and secondly by the reactions involving $\mathrm{C}_{2}$ species. This has also been reported by $\mathrm{Xu}$ and $\mathrm{Konnov}^{18}$, where the $\mathrm{H} / \mathrm{O} / \mathrm{C}_{1}$ reactions dominate under fuel-lean conditions while $\mathrm{C}_{2}$ reactions influence more under fuel-rich conditions. The sensitivity spectra of the same reactions in the three skeletal mechanisms and the detailed mechanism are similar, indicating that the species and reactions after the reductions still soundly characterize the laminar flame speed. To better understand the variances among these mechanisms, reaction path way analyses at the same conditions as the sensitivity analysis were carried out and shown in the supporting information. Comparing the skeletal mechanisms with the detailed one, it can be found that all the skeletal mechanisms faithfully capture the major pathways through which the fuel molecule breaks into small radical. From the above comparisons, the three skeletal mechanisms show negligible difference. To minimize the 
computational cost, the smallest DRGEPSACSP mechanism will be selected as the optimized one for the following practical combustor modeling.

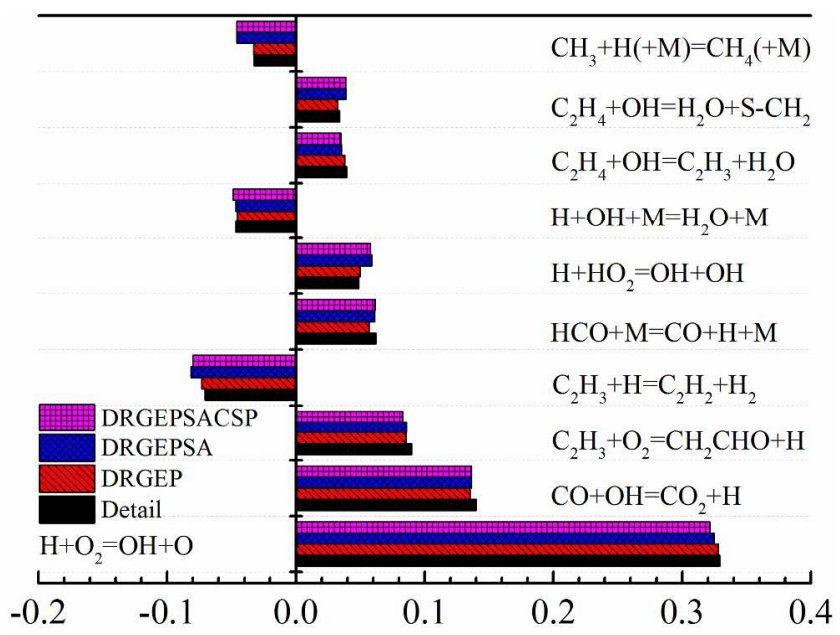

Figure 7. Sensitivity analysis of laminar flame speed for stoichiometric ethylene-air mixture based on the skeletal and detailed mechanisms at an unburned mixture temperature of $298 \mathrm{~K}$ and pressure of $1.0 \mathrm{~atm}$.

\section{SCRAMJET COMBUSTOR MODELING}

\subsection{Experiment Description}

The experiment was carried out in a directly connected-pipe test station by Situ et al. ${ }^{35}$. The supersonic combustion test model schematized in Figure 8 is a two-dimensional (2-D) duct with a length of $1100 \mathrm{~mm}$. The rectangular duct inlet is $65 \mathrm{~mm}$ in height and $40 \mathrm{~mm}$ in width. The 370-mm-long mixing section is followed by a $3.6^{\circ}$ unilateral expansion section till the exit of the combustor. The vitiated air at $\mathrm{Ma}=2.15$ was supplied by a hydrogen-based heater to increase its stagnation temperature to $1700 \mathrm{~K}$. Oxygen was replenished to the vitiated air to recover the oxygen concentration to the standard air. The composition of vitiated air stream was calculated based on the amount of hydrogen consumed and oxygen replenished to reach desired stagnation temperature and pressure by assuming complete combustion. 


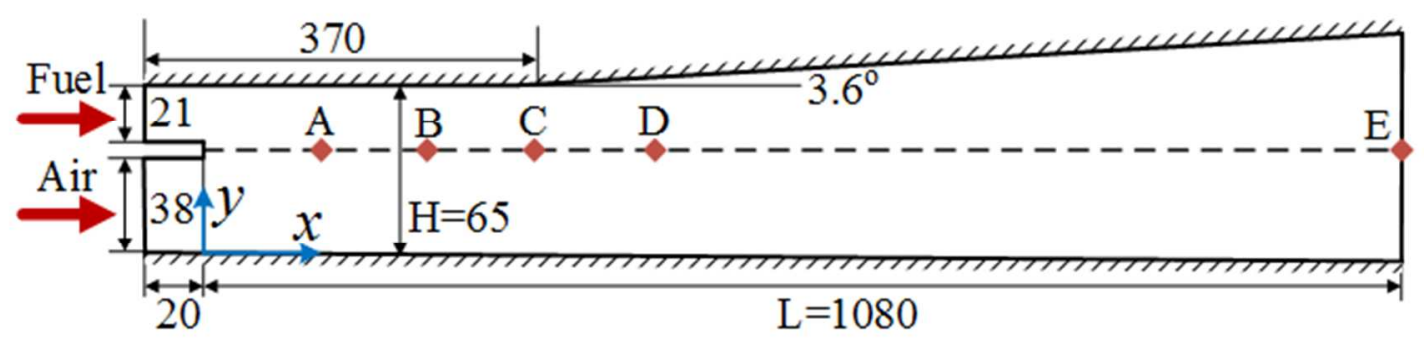

Figure 8. Schematic of the model combustor (unit in $\mathrm{mm}$ ) with $\hat{x}_{A}=0.1, \hat{x}_{B}=0.2, \hat{x}_{C}=$ $0.3, \hat{x}_{D}=0.4, \hat{x}_{E}=1.0$.

The $\mathrm{Ma}=1.25$ fuel stream is composed of hot gas products from the kerosene/air combustion in an upstream subsonic dump combustor. Since direct measurement of the kerosene/air reaction products is experimentally intractable, the composition of the fuel stream was obtained by employing a simplified chemistry model ${ }^{35}$. Firstly, after endothermic reactions, gaseous ethylene was used as surrogate fuel intended to represent the products of thermal-cracked kerosene ${ }^{36}$. Then, the mass fractions of involved species were obtained by adopting one-step global reaction to match the combustion efficiency based on measured stagnation temperature and pressure at the exit of the subsonic bump combustor. Both the vitiated air and the fuel are axially injected into the supersonic combustor and then split by a 6-mm-high splitter. The static pressure along the flow direction was measured on the lower wall with 23 pressure taps, and on the upper wall with 13 pressure taps. The experimental setups including specific compositions of both fuel and air stream are summarized in Table 3.

Table 3. Numerical setup for the supersonic combustor simulation

\begin{tabular}{|c|c|c|}
\hline Parameter & Air & Fuel \\
\hline $\mathrm{P}(\mathrm{MPa})$ & 0.0977 & 0.1731 \\
\hline $\mathrm{Ma}$ & 2.15 & 1.25 \\
\hline $\mathrm{T}(\mathrm{K})$ & 491.9 & 1771.9 \\
\hline $\mathrm{Y}_{\mathrm{N} 2}$ & 0.7150 & 0.6067 \\
\hline
\end{tabular}




\begin{tabular}{|c|c|c|}
\hline $\mathrm{Y}_{\mathrm{O} 2}$ & 0.2330 & 0.0103 \\
\hline $\mathrm{Y}_{\mathrm{C} 2 \mathrm{H} 4}$ & 0.0 & 0.1059 \\
\hline $\mathrm{Y}_{\mathrm{H} 2 \mathrm{O}}$ & 0.0520 & 0.1566 \\
\hline $\mathrm{Y}_{\mathrm{CO} 2}$ & 0 & 0.1205 \\
\hline
\end{tabular}

\subsection{Computational Methodology}

The spatially filtered governing equations for mass, momentum, species and energy in LES are solved. The gas state is described by the ideal gas law. The viscosity is given by Sutherland's law. Following the thermally perfect gas assumption, thermodynamic data are obtained from the NIST-JANAF database ${ }^{37}$. The thermal and mass diffusivities are obtained by assuming constant Prandtl number $(\operatorname{Pr}=0.7)$ and Schmidt number $(S c=0.7)$.

The subgrid turbulence terms are closed by employing the one-equation kinetic energy model in which a transport equation of subgrid kinetic energy is solved. ${ }^{38}$ Turbulent Prandtl number $P r_{\mathrm{t}}$ and Schmidt number $S c_{\mathrm{t}}$ are set to 0.72 and 0.9 , respectively. The filtered reaction rates are modeled using a heterogeneous multi-scale method of the first generation, i.e., the partially stirred reactor (PaSR) model. ${ }^{39}$

The three-dimensional, Favre-filtered Navier-Stokes equations together with scalar transport equations for species are solved using a density-based solver, astroFoam, which is developed based on the OpenFoam CFD package ${ }^{40}$. The convective fluxes at faces are constructed using the second-order TVD (Total Variation Diminishing) scheme. The time-integration is advanced by the second-order Crank-Nicholson scheme ${ }^{41}$. Details of the numerical methods can refer to Wu et al. $^{2}$. The code has been extensively validated for non-reactive highly underexpanded jets ${ }^{42}$ and supersonic combustions. ${ }^{2,10}$

\subsection{Numerical Implementation}


The schematic of the computational model is shown in Figure 8, in which the streamwise and transverse coordinates $\hat{\mathrm{x}}$ and $\hat{\mathrm{y}}$ have been normalized respectively using the inlet length $L$ and height $H$. Due to its 2-D flow pattern, a twentieth of the spanwise width of the combustor (2 mm in the $\mathrm{Z}$ direction) is considered. The block-structured hexahedral grid is employed with clustering around the shear layer initiating from the splitter. The shear layer is resolved by a refined grid with 61 transverse cells and 5 spanwise grids. The mean and maximum grid sizes in the mixing zone are $0.2 \mathrm{~mm}$ and $0.35 \mathrm{~mm}$ respectively. Since main combustion takes place in the interior mixing region, upper and lower combustor walls are treated as slip wall to relieve the prohibitive grid resolution in the near-wall regions. Such alleviation in the computational cost makes it possible for the combustion modeling based on the detailed mechanism. For grid sensitivity analysis, three grid sets with $0.14,0.28$ and 0.36 million cells were employed in the present study.

Fixed values are used for all variables on the combustor inlet except the velocity, which is specified as the superposition of a mean profile and sinusoidal perturbations with $5 \%$ amplitude of the mean values. All the variables are extrapolated from the interior on the combustor exit. Walls constituting the splitter are treated as adiabatic non-slip condition. The time step is around $2 \times 10^{-8} \mathrm{~s}$ which corresponds to a maximum Courant-Friedrich-Lewy (CFL) number of 0.4. The detailed UCSD mechanism and the DRGEPSACSP skeletal mechanism are adopted. The coupling of high-resolution LES with the detailed mechanism offers us the uppermost information about the reacting flow taking place in the combustor for remedy of scarce highresolution measurements available in scramjet experiment, especially associated to chemical kinetics. 
In the following discussion, the pressure, temperature, and velocity are scaled by the air stream properties as $\hat{\mathrm{p}}=\mathrm{p} / \mathrm{p}_{\infty}, \widehat{\mathrm{T}}=\mathrm{T} / \mathrm{T}_{\infty}$ and $\widehat{\mathrm{U}}=\mathrm{U} / \mathrm{U}_{\infty}$. The heat release rate $\mathrm{dQ}$ is scaled in form of $\mathrm{d} \widehat{\mathrm{Q}}=d Q / \mathrm{C}_{\mathrm{p}} \mathrm{T}$, where $\mathrm{C}_{\mathrm{p}}$ and $\mathrm{T}$ are local constant-pressure specific heat and temperature respectively. The flow-through time is defined as $\mathrm{t}_{\mathrm{f}}=\mathrm{L} / \mathrm{U}_{\infty} \approx 1.2 \mathrm{~ms}$. The cold flow modeling runs totally for $8 t_{f}$, where $2 t_{f}$ is for the development of a statistically steady state and $6 t_{f}$ is for the statistical data collection. For the combustion modeling, a longer run time of $12 t_{\mathrm{f}}$ is needed to complete the reacting flow evolution and data collection.

\section{FIDELITY EVALUATION OF THE SKELETAL MECHANISM IN COMBUSTOR MODELING}

\subsection{Numerical Validation}

Figure 9 shows the results of grid convergence study. The streamwise pressure across the middle line of the splitter shows that all the meshes generate almost identical profiles for the non-reacting flow. This indicates that the mesh resolution has been fine enough to capture the intricate shock/expansion waves filled flow field in the combustor. As a tradeoff, the mediumsize grid with 0.28 million cells was used in the following modeling.

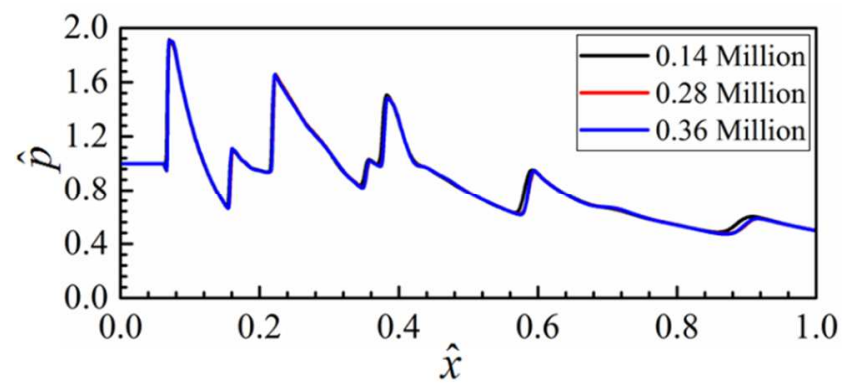

Figure 9. Grid convergence of pressure distribution on the line across the middle of the splitter for non-reacting flow modeling. 
To describe the flow field, the pressure contours predicted by using the skeletal and detailed mechanisms are shown in Figure 10. The main flow and wave structures presented by the two contours are similar qualitatively. The upper shear layer experiences an expansion followed by an oblique shock, which is reflected on the upper wall and interacts with the one reflected from the lower wall. The first shock interaction point locates at $\hat{x}=0.115$ and is off-center in the $\mathrm{Y}$ direction due to the asymmetric domain. Two additional intersection points can be observed in the downstream.

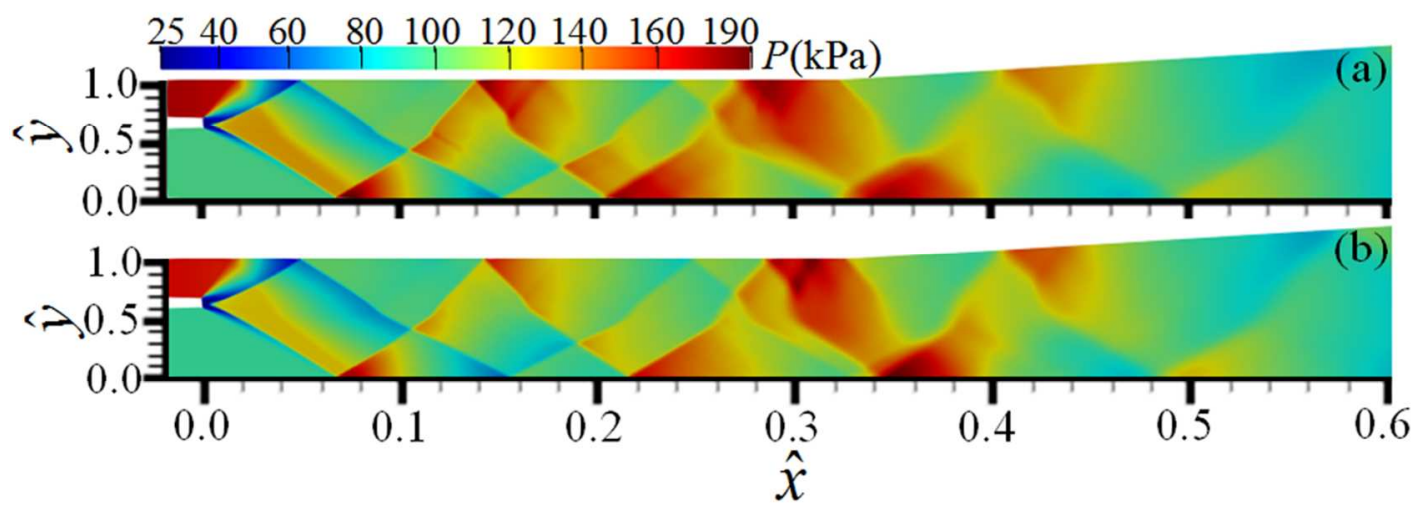

Figure 10. Time-averaged pressure contours predicted by (a) the DRGEPSACSP mechanism and (b) the detailed mechanism (the far downstream of the combustor is omitted for better visualization).

Figure 11 compares the predicted pressure profiles on the upper and lower walls of the combustor with the available experimental data. The pressure profiles predicted by the detailed mechanism agree with the measurements satisfactorily, especially the locations of turning points are well captured. The sharp turning angles also indicate that more pressure taps should be laid to allow a denser sampling in experiment. The pressure profiles predicted by the skeletal mechanism coincide with those by the detailed mechanism before $\hat{x}=0.1$, where the flow is less influenced by the combustion. Since there, the predicted pressure profiles derivate slightly from 
the detailed ones, especially around the peaks between $\hat{x}=0.3$ to 0.7 . However, the mean relative errors are still as limited as $4.8 \%$ and $3.5 \%$ for lower and upper walls respectively.

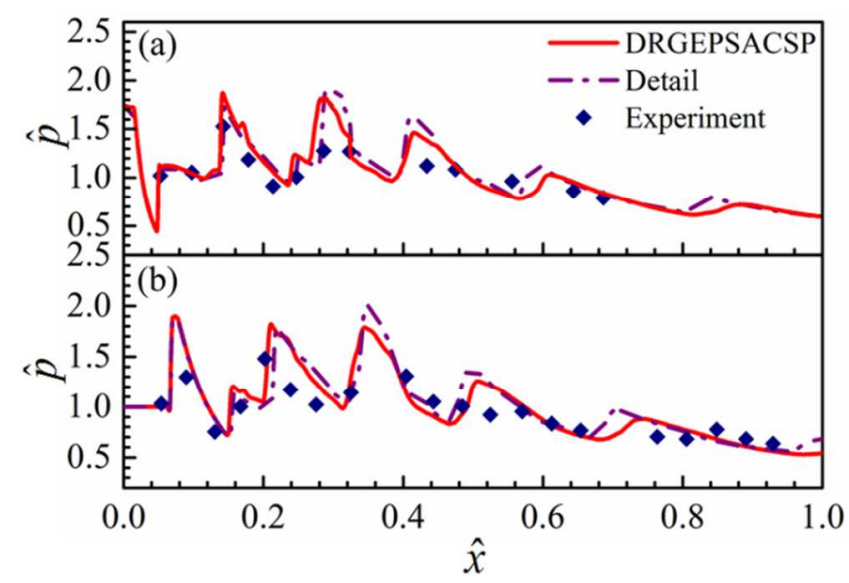

Figure 11. Comparison of the pressure on the (a) upper and (b) lower walls predicted by the DRGEPSACSP and detailed mechanisms with the experimental measurements.

\subsection{Second Level of Fidelity Evaluation: Global Performance Analysis}

For scramjet combustor design and global performance assessment, one-dimensional analysis is the most powerful and efficient tool ${ }^{43}$. By performing mass-weighted average on the crosssection at each streamwise location, the pseudo one-dimensional streamwise distribution of static pressure and Mach number can be obtained. From Figure 12(a), at locations before $\hat{x}=0.1$ or after $\hat{\mathrm{x}}=0.8$, the pressure distributions predicted by two mechanisms are almost identical, except for the slight difference between these two locations. In this intermediate region, the pressure by the skeletal mechanism is slightly overpredicted before $\hat{\mathrm{x}}<0.28$ and then underpredicted in comparison with the detailed one. The calculated Mach number profiles show the opposite trend since the static pressure is a decreasing function of Ma. The Mach number is always larger than unity, indicating a supersonic operating mode. The maximum and mean relative errors are $8.9 \%$ and $3.7 \%$ for the pressure, while $4.2 \%$ and $1.8 \%$ for the Ma. Generally, 
the predictions by the skeletal mechanism show reasonably good agreement with those by the detailed mechanism.

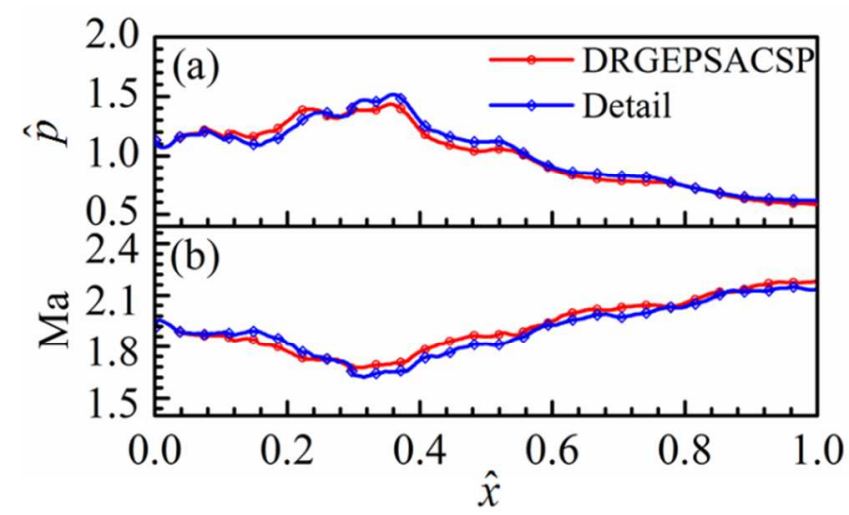

Figure 12. Pseudo one-dimensional streamwise distribution of pressure and Mach number predicted by the DRGEPSACSP and detailed mechanisms.

In the experiment process of scramjet combustor, thermochemical data such as temperature and stable combustion products are usually probed at the combustor exit to assess the engine's global performance. In this regard, main combustion products including $\mathrm{H}_{2} \mathrm{O}$ and $\mathrm{CO}_{2}$ along with static temperature are sampled at the combustor exit for comparison. In Figure 13(a), the mass fractions of $\mathrm{H}_{2} \mathrm{O}$ predicted by two mechanisms manifest only slight deviations in the central region. The mass fraction of $\mathrm{CO}_{2}$ and the static temperature profiles in Figure 13 (b)-(c) also show similar trends like $\mathrm{Y}_{\mathrm{H} 2 \mathrm{O}}$. 


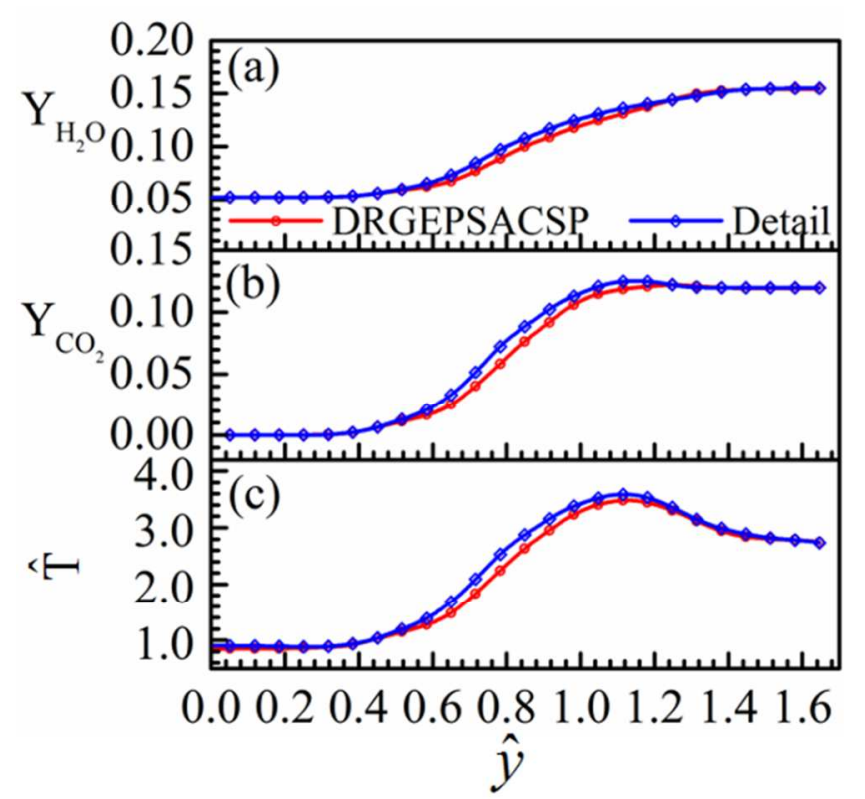

Figure 13. Time-averaged mass fractions of $\mathrm{H}_{2} \mathrm{O}$ and $\mathrm{CO}_{2}$, and temperature on the combustor exit predicted by the DRGEPSACSP and detailed mechanisms.

To quantitatively assess the engine's global performance, combustion efficiency and total pressure loss can be calculated based on the sampled data at the combustor exit. The total pressure loss is defined as ${ }^{44}$ :

$$
\eta_{t}=1-\frac{\int p_{0, \text { exit }} \rho u d A}{\int p_{0, \text { inlet }} \rho u d A}
$$

where $\mathrm{p}_{0 \text {,inlet }}$ and $\mathrm{p}_{0 \text {,exit }}$ are the total pressures at combustor inlet and exit, respectively; $\rho$ is the density, $\mathrm{u}$ is the velocity component in the streamwise direction, and $d A$ is the incremental area projection in the streamwise direction. The overall total pressure losses are $45.5 \%$ and $42.5 \%$ for the skeletal and the detailed mechanisms respectively. The definition of combustion efficiency is reformulated to use the heat release as the combustion progress indicator, rather than the traditional definition ${ }^{45}$ based on $\mathrm{CO}_{2}$ or $\mathrm{H}_{2} \mathrm{O}$ since these species are also contained in the fuel stream. The reformulated combustion efficiency is given by: 


$$
\eta_{c}=\frac{\int \rho \operatorname{udQ}_{\text {exit }} \mathrm{dA}}{\sum_{\text {inlet }}\left(\dot{\mathrm{m}}_{\text {fuel }} \mathrm{Y}_{\mathrm{c}_{2 \mathrm{H}_{4}}}\right) \mathrm{q}_{\mathrm{c}}}
$$

in which $\mathrm{dQ}_{\mathrm{exit}}$ is the heat release the combustor outlet, $\dot{\mathrm{m}}_{\text {fuel }}$ is the mass flow rate of the fuel, $\mathrm{Y}_{\mathrm{c}_{2} \mathrm{H}_{4}}$ is the mass fraction of ethylene in the fuel stream at the combustor inlet, and $\mathrm{q}_{\mathrm{c}}$ is the heat of combustion of ethylene under standard condition. The overall combustion efficiencies are $58.2 \%$ and $57.8 \%$ for the skeletal and detailed mechanisms respectively. The overall combustion efficiencies and total pressure losses predicted by the skeletal mechanisms agree well with those by the detailed mechanism which substantiates the high-level fidelity of the present skeletal mechanism when coupling with flow modeling.

Great computational cost, which is one of the main concerns in supersonic combustion modeling, is saved by using the skeletal mechanism. For a typical reacting flow modeling, the skeletal mechanism costs only on fifth of the computation time needed by the detailed one.

\subsection{Third Level of Fidelity Evaluation: Flame Structure Analysis}

It can be seen that the spatial distribution of $\mathrm{OH}$ radical in Figure 14 shows relatively large derivation between the predictions by the two mechanisms. The skeletal mechanism predicts the production of $\mathrm{OH}$ radical far upstream than that by the detailed mechanism. The first local extremum in the prediction by the skeletal mechanism locates at around $\hat{\mathrm{x}} \approx 0.15$, which is almost half shorter than the location of $\hat{\mathrm{x}} \approx 0.32$ predicted by the detailed mechanism. The flame structure represented by the $\mathrm{CO}$ radical in Figure 15 shows less difference between the predictions by the two mechanisms, with only noticeable derivation in $0.1<\hat{\mathrm{x}}<0.2$. 
predicts a shorter ignition distance. At locations C and D, good agreements are achieved, which demonstrates the accuracy of the skeletal mechanism in the post-ignition stage.

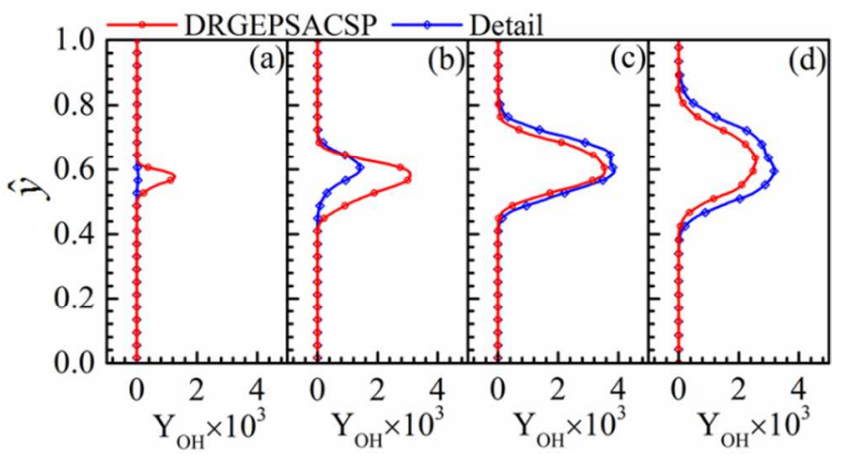

Figure 16. Time-averaged $\mathrm{OH}$ distributions predicted by the DRGEPSACSP and detail mechanisms at different streamwise locations: (a) location $\mathrm{A}$, (b) location $\mathrm{B}$, (c) location $\mathrm{C}$ and (d) location D.

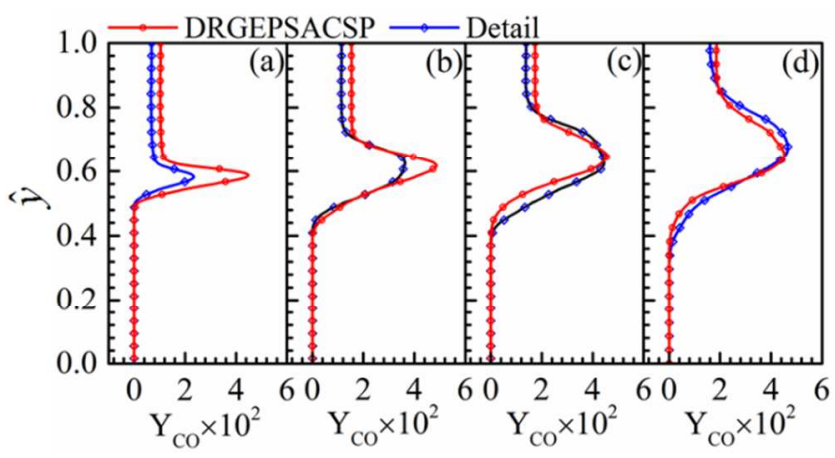

Figure 17. Time-averaged $\mathrm{CO}$ distributions predicted by the DRGEPSACSP and detail mechanisms at different streamwise locations: (a) location $\mathrm{A}$, (b) location $\mathrm{B}$, (c) location $\mathrm{C}$ and (d) location D.

In order to assess the kinetic performance in the global sense, pseudo one-dimensional distributions of $\mathrm{OH}, \mathrm{CO}$ and heat release rate predicted by the two mechanisms are compared in Figure 18. The value at the streamwise location is calculated as the mass flux weighted average on the corresponding cross-section perpendicular to the axis. The $\mathrm{OH}$ distributions have 
relatively large difference for the two mechanism around $\hat{x} \approx 0.6$. As has been analyzed before, the production of $\mathrm{OH}$ radical starts at $\hat{\mathrm{x}} \approx 0.08$ for the skeletal mechanism and $\hat{\mathrm{x}} \approx 0.16$ for the detailed mechanism. Although the production of $\mathrm{OH}$ has been significantly delayed in the detailed mechanism, its peak value is nearly doubled compared with the skeletal mechanism. Further downstream, these two profiles collide with each other. The difference in the CO distributions is larger before $\hat{x}=0.2$ and then maintains at a low level till the exit. The nondimensional distribution of heat release rate along the streamwise distance is usually the most concerned since it exerts the major influence on the wall heat flux distribution and thereby the thermal protection design. From Figure 18(c), larger difference exists in range $0.08<\hat{\mathrm{x}}<0.4$. The skeletal mechanism predicts an earlier heat release at $\hat{\mathrm{x}} \approx 0.08$, but its peak magnitude is just half of that predicted by the detailed one, which takes place slightly downstream at $\hat{\mathrm{x}} \approx 0.16$. Referring to Figure 11-12, although the skeletal mechanism shows some deficiency in predicting the concentrations of species mainly in the ignition stage, the flow characteristics, e.g., pressure and Ma are still in reasonably good agreements with those predicted by the detailed mechanism. The current skeletal mechanism is suitable for the performance evaluation of scramjet combustors, where accurate pressure distribution, combustion efficiency, and total pressure loss are required. However, if the focus is the auto-ignition process and/or the combustion instability, chemical mechanisms with a higher fidelity should be adopted to give more reliable information on the distributions of key species. A balance between the computational efficiency and the modeling fidelity determines the reduction degree of the mechanism. 


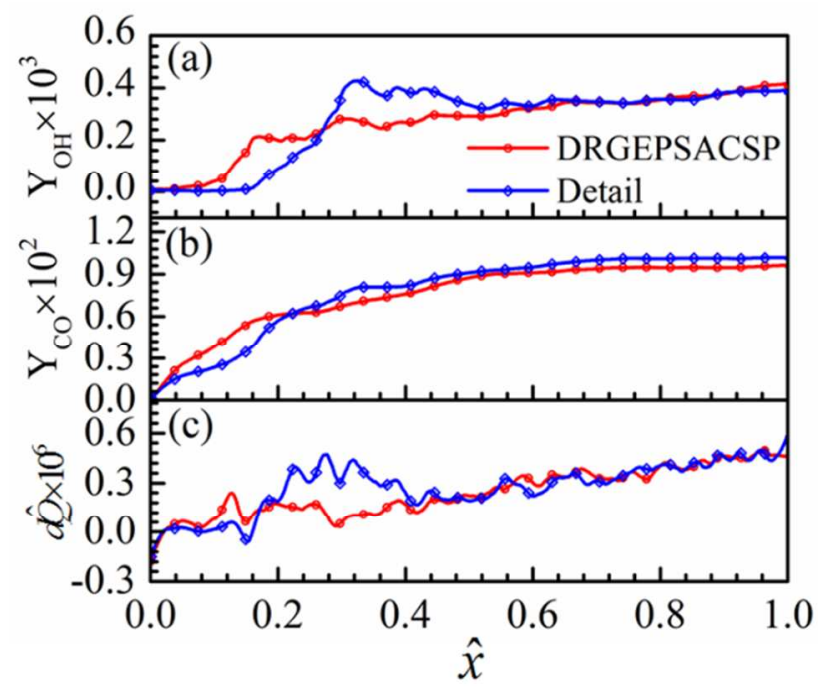

Figure 18. Pseudo one-dimensional streamwise distribution of mass fractions of $\mathrm{OH}$ and $\mathrm{CO}$, and heat release rate predicted by the DRGEPSACSP and detail mechanisms.

\section{CONCLUDING REMARKS}

In this study, a skeletal mechanism for ethylene-air combustion is developed and validated for supersonic combustion modeling. Based on a selected detailed mechanism, DRGEP, SA and CSP methods were performed in different combinations to obtain the final skeletal mechanisms. The first level of fidelity validation is conducted through comparing the kinetic properties of the three skeletal mechanisms with the original detailed mechanism. The three skeletal mechanisms show negligible difference in the first level of fidelity validation. To minimize the computational cost, the smallest DRGEPSACSP mechanism is selected for the remaining levels of fidelity validation.

The application of the DRGEPSACSP mechanism in a realistic scramjet combustor modeling shows reasonably good agreements in the predictions of pressure distribution, combustion efficiency, and total pressure loss, in comparison with those by the detailed mechanism. The flame structure analysis shows the deficiency of the skeletal mechanism in predicting the 
distributions of key species mainly in the ignition stage. However, the flow characteristics, e.g., pressure and Ma and are still in reasonably good agreements with those predicted by the detailed mechanism. Reliable information on the distributions of key species is usually only required for the study of ignition process or combustion instability. The current skeletal mechanism gains more advantage in the performance evaluation of scramjet combustors, due to its computational efficiency and good predictive capability of the combustion-adjoint aerodynamic characteristics. 


\title{
ASSOCIATED CONTENT
}

\section{Supporting Information}

The following files are available free of charge.

Extended verification of the detailed and skeletal mechanisms (PDF)

Reaction path diagrams for the laminar flame speed simulation (PDF)

The DRGEPSACSP (24S/86R) skeletal mechanism (PDF)

\section{AUTHOR INFORMATION}

\section{Corresponding Author}

*E-mail: weiyao@imech.ac.cn (Wei Yao); xfan@imech.ac.cn (Xuejun Fan)

\section{Notes}

The authors declare no competing financial interest.

\author{
ACKNOWLEDGMENTS \\ The work was supported by Training Program of the Major Research Plan of the National \\ Natural Science Foundation of China (Grant No. 91641110) and National Natural Science \\ Foundation of China (Grant No. 11502270).
}




\section{REFERENCES}

(1) Li, J.; Zhang, L.; Choi, J. Y.; Yang, V.; Lin, K.-C., Ignition Transients in a Scramjet Engine with Air Throttling Part II: Reacting Flow. J. Propul. Power. 2014, 31(1), 79-88.

(2) Wu, K.; Zhang, P.; Yao, W.; Fan, X., Numerical Investigation on Flame Stabilization in DLR Hydrogen Supersonic Combustor with Strut Injection. Combust. Sci. Tehcnol. 2017, 1-26.

(3) Fureby, C., Large Eddy Simulation of Combustion Instabilities in a Jet Engine Afterburner Model. Combust. Sci. Tehcnol. 2000, 161(1), 213-243.

(4) Curran, E. T., Scramjet Engines: The First Forty Years. J. Propul. Power. 2001, 17(6), 11381148.

(5) Fan, X. J.; Zhong, F. Q.; Yu, G.; Li, J. G.; Sung, C. J., Catalytic Cracking and Heat Sink Capacity of Aviation Kerosene Under Supercritical Conditions. J. Propul. Power. 2009, 25(6), 1226-1232.

(6) Law, C. K.; Sung, C. J.; Wang, H.; Lu, T., Development of comprehensive detailed and reduced reaction mechanisms for combustion modeling. AIAA J. 2003, 41(9), 1629-1646.

(7) Sun, W.; Chen, Z.; Gou, X.; Ju, Y., A path flux analysis method for the reduction of detailed chemical kinetic mechanisms. Combust. Flame. 2010, 157(7), 1298-1307.

(8) Hui, X.; Niemeyer, K. E.; Brady, K. B.; Sung, C.-J., Reduced Chemistry for Butanol Isomers at Engine-Relevant Conditions. Energy Fuels 2017, 31(1), 867-881.

(9) Wang, X.; Liu, H.; Zheng, Z.; Yao, M., A Skeletal Mechanism of a Biodiesel Surrogate Fuel for Compression Ignition Engines. Energy Fuels 2015, 150126152354001.

(10) Yao, W.; Yuan, Y.; Li, X.; Wang, J.; Fan, X., A comparative study of elliptical and round scramjet combustors by Improved Delayed Detached Eddy Simulation. In 21st AIAA 
International Space Planes and Hypersonics Technologies Conference, American Institute of Aeronautics and Astronautics: 2017.

(11) Gregory P. Smith, D. M. G., Michael Frenklach, Nigel W. Moriarty, Boris Eiteneer, Mikhail Goldenberg, C. Thomas Bowman, Ronald K. Hanson, Soonho Song, William C. Gardiner, Jr., Vitali V. Lissianski, and Zhiwei Qin; ( http://www.me.berkeley.edu/gri mech/).

(12) Marinov, N. M.; Pitz, W. J.; Westbrook, C. K.; Vincitore, A. M.; Castaldi, M. J.; Senkan, S. M.; Melius, C. F., Aromatic and Polycyclic Aromatic Hydrocarbon Formation in a Laminar Premixed n-Butane Flame. Combust. Flame. 1998, 114(1-2), 192-213.

(13) "Chemical-Kinetic Mechanisms for Combustion Applications", S. D. M. w. p., Mechanical and Aerospace Engineering (Combustion Research), University of California at San Diego; (http://combustion.ucsd.edu).

(14) Hai Wang, X. Y., Ameya V. Joshi, Scott G. Davis, Alexander Laskin, Fokion Egolfopoulos and Chung K. Law, USC Mech Version II. High-Temperature Combustion Reaction Model of $\mathrm{H}_{2} / \mathrm{CO} / \mathrm{C}_{1}-\mathrm{C}_{4}$ Compounds; ( http://ignis.usc.edu/USC_Mech_II.htm).

(15) Wang, H., Laskin,A, A comprehensive kinetic model of ethylene and acetylene oxidation at high temperatures,Progress Report for an AFOSR New World Vista Program. 1998.

(16) Konnov, A., Development and validation of a detailed reaction mechanism for the combustion modeling. Eurasian Chem.-Technol. J. 2000, 2(3-4), 257-264.

(17) Qin, Z.; Lissianski, V. V.; Yang, H.; Gardiner, W. C.; Davis, S. G.; Wang, H., Combustion chemistry of propane: a case study of detailed reaction mechanism optimization. Proc. Combust. Inst. 2000, 28(2), 1663-1669.

(18) $\mathrm{Xu}, \mathrm{C}$; K Konnov, A. A., Validation and analysis of detailed kinetic models for ethylene combustion. Energy 2012, 43(1), 19-29. 
(19) Segal, C., The scramjet engine: processes and characteristics. Cambridge University Press: Cambridge, 2009.

(20) Kee, R. J.; Rupley, F. M.; Miller, J. A. Chemkin-II: A Fortran chemical kinetics package for the analysis of gas-phase chemical kinetics; Sandia National Labs., Livermore, CA (USA): 1989. (21) Danielle, K.; Matthew, R.; Joel, H.; Eric, P., Ignition Measurements of Ethylene-OxygenDiluent Mixtures With and Without Silane Addition. In 42nd AIAA Aerospace Sciences Meeting and Exhibit, American Institute of Aeronautics and Astronautics: 2004.

(22) Kumar, K.; Mittal, G.; Sung, C.; Law, C., An experimental investigation of ethylene $/ \mathrm{O}_{2} /$ diluent mixtures: Laminar flame speeds with preheat and ignition delays at high pressures. Combust. Flame. 2008, 153(3), 343-354.

(23) Egolfopoulos, F. N.; Zhu, D. L.; Law, C. K., Experimental and numerical determination of laminar flame speeds: Mixtures of $\mathrm{C}_{2}$-hydrocarbons with oxygen and nitrogen. Symp. (Int.) Combust. 1991, 23(1), 471-478.

(24) Lu, T.; Law, C. K., Toward accommodating realistic fuel chemistry in large-scale computations. Prog. Energy Combust. Sci. 2009, 35(2), 192-215.

(25) Turányi, T., Sensitivity analysis of complex kinetic systems. Tools and applications. $J$. Math. Chem. 1990, 5(3), 203-248.

(26) Lu, T.; Law, C. K., A directed relation graph method for mechanism reduction. Proc. Combust. Inst. 2005, 30(1), 1333-1341.

(27) Pepiot desjardins, P.; Pitsch, H., An efficient error-propagation-based reduction method for large chemical kinetic mechanisms. Combust. Flame. 2008, 154(1-2), 67-81. 
(28) Niemeyer, K. E.; Sung, C.-J.; Raju, M. P., Skeletal mechanism generation for surrogate fuels using directed relation graph with error propagation and sensitivity analysis. Combust. Flame. 2010, 157(9), 1760-1770.

(29) Oluwole, O. O.; Shi, Y.; Wong, H.-W.; Green, W. H., An Exact-Steady-state Adaptive Chemistry method for combustion simulations: Combining the efficiency of reduced models and the accuracy of the full model. Combust. Flame. 2012, 159(7), 2352-2362.

(30) Rein, M., The partial $\square$ equilibrium approximation in reacting flows. Phys.Fluids A 1992, $4(5), 873-886$.

(31) Maas, U.; Pope, S. B., Simplifying chemical kinetics: Intrinsic low-dimensional manifolds in composition space. Combust. Flame. 1992, 88(3), 239-264.

(32) Lu, T.; Ju, Y.; Law, C. K., Complex CSP for chemistry reduction and analysis. Combust. Flame. 2001, 126(1), 1445-1455.

(33) Niemeyer, K. E.; Sung, C.-J., On the importance of graph search algorithms for DRGEPbased mechanism reduction methods. Combust. Flame. 2011, 158(8), 1439-1443.

(34) Larsson, A.; Zettervall, N.; Hurtig, T.; Nilsson, E. J. K.; Ehn, A.; Petersson, P.; Alden, M.; Larfeldt, J.; Fureby, C., Skeletal Methane-Air Reaction Mechanism for Large Eddy Simulation of Turbulent Microwave-Assisted Combustion. Energy Fuels 2017, 31(2), 1904-1926.

(35) Situ, M.; Sun, Y.; Zhang, S.; Wang, C., Investigation of supersonic combustion of hydrocarbon fuel-riched hot gas in scramjet combustor. In 35th Joint Propulsion Conference and Exhibit, American Institute of Aeronautics and Astronautics: 1999.

(36) Molvik, G.; Bowles, J.; Huynh, L. O. C., Analysis of a hydrocarbon scramjet with augmented preburning. In 28th Joint Propulsion Conference and Exhibit, American Institute of Aeronautics and Astronautics: 1992. 
(37) Chase, M., W, JANAF Thermochemical Tables. J. Phys. J. Chem. Ref. Data 1974, 3(2), $311-480$.

(38) Yoshizawa, A., Statistical theory for compressible turbulent shear flows, with the application to subgrid modeling. Phys. Fluids 1986, 29(7), 2152.

(39) Karlsson, A. Modeling auto-ignition, flame propagation and combustion in non-stationary turbulent sprays. PhD Thesis, Chalmers University of Technology, 1995.

(40) Weller, H. G.; Tabor, G.; Jasak, H.; Fureby, C., A Tensorial Approach to CFD using Object Oriented Techniques. Comput. Physics. 1997, 12(6), 620-631.

(41) Baba-Ahmadi, M. H.; Tabor, G., Inlet conditions for LES using mapping and feedback control. Comput. Fluids. 2009, 38(6), 1299-1311.

(42) Li, X.; Yao, W.; Fan, X., Large-Eddy Simulation of Time Evolution and Instability of Highly Underexpanded Sonic Jets. AIAA J. 2016, 54(10), 3191-3211.

(43) Tian, L.; Chen, L.; Chen, Q.; Li, F.; Chang, X., Quasi-One-Dimensional Multimodes Analysis for Dual-Mode Scramjet. J. Propul. Power. 2014, 30(6), 1559-1567.

(44) Baurle, R.; Mathur, T.; Gruber, M.; Jackson, K., A numerical and experimental investigation of a scramjet combustor for hypersonic missile applications. In 34th AIAA/ASME/SAE/ASEE Joint Propulsion Conference and Exhibit, American Institute of Aeronautics and Astronautics: 1998.

(45) Kumaran, K.; Babu, V., Investigation of the effect of chemistry models on the numerical predictions of the supersonic combustion of hydrogen. Combust. Flame. 2009, 156(4), 826-841. 